\title{
Research and Analysis on the Development of Regional Teachers' Information Literacy
}

\author{
Weigang Guo ${ }^{1, a^{*}}$ and Zhu Yang ${ }^{2, b}$ \\ ${ }^{1}$ School of Electronic and Information Engineering of Foshan University, Guangdong, China \\ ${ }^{2}$ Information Center of Foshan University, Guangdong, China \\ awgguo@qq.com, byangzhu@fosu.edu.cn
}

Keywords: Information literacy; Information consciousness and attitude; Knowledge and skills; Application and innovation; Information technology teaching practice

\begin{abstract}
With the development of the mobile Internet, Big data and other new information technology, the application of information technology in education is more and more extensive. The quality of teachers' information literacy directly affects the effect of the implementation of education information. In this paper, the 69 primary and secondary schools in Foshan City, Guangdong Province, China, were investigated by means of questionnaire survey, discussion with teachers. Large amounts of data on the subject of teachers' information literacy are collected. Based on the reliability analysis and validity analysis of the questionnaire data, the data were analyzed by visual analysis. This paper mainly analyzes and studies the teacher's information awareness and attitude, knowledge and skills, application and innovation, information technology teaching practice and so on. The results show that the overall level of information literacy of teachers in Foshan city is higher, and is in the leading position in the country. The main problems are lack of evaluation mechanism of the performance. And the educational information technology research capability is not strong enough. It is suggested that in the future development the educational information technology training and educational technology research should be strengthened to greatly improve the teachers' information literacy and to meet the requirements of the development of the times.
\end{abstract}

\section{Introduction}

With the rapid development of information technology, multimedia technology and network technology, the tide of e-education develops swiftly. Promoting teachers' information literacy is the inevitable requirement of the development of e-education [1]. The United States of America is the most developed countries in the information industry development, at the same time it is the first country of carrying out primary and secondary information literacy education in the world. Teachers have high information literacy [2]. In China, as a result of the overall economic development level and the information level is not high, the teacher and student's information literacy needs to be further developed and improved [3,4,5]. A research about Jiangxi Province shows that the middle school teachers' information literacy is in the middle level of the whole, a lot of aspects should be improved [6]. And, in Dalian City Liaoning Province, the general problems of teachers' information literacy in junior high schools include: lower consciousness of teachers' information needs, lack of information knowledge and skills, non-ideal effect of application of information technology in the teaching, and ignore of information ethics and legal security [7]. Many researchers have put forward a lot of valuable suggestions for the information literacy of the subject teachers. It is suggested that teachers' awareness, attitudes, and personal needs should be taken into account in the process of integrating ICT into their professional practice and self-development $[8,9,10]$. From the previous analysis, we can see that the research result of teachers' information literacy is less. This paper takes Foshan City, one of the most developed areas of information technology, as the research object, through the questionnaire and discussion with teachers, to study the status of regional teachers' information literacy, and put forward suggestions for improvement. 


\section{Methodology}

The main research method used in this paper includes questionnaire and discussion with teachers.

Questionnaire. On the basis of literature research and communicating with the primary and secondary school teachers and educational technology departments, two questionnaires were drawn up, including "computer teacher questionnaire", "ordinary teacher questionnaire". These questionnaires were carried out in 69 primary and secondary schools in Foshan city online. Table 1 shows the statistics of the questionnaires distributed and recovered. The reliability and validity of the questionnaires were analyzed. For the data collected by the questionnaires, multiple linear regression analysis, data envelopment analysis and other mathematical models are used to do a lot of detailed statistical analysis.

Table 1 The statistics of the questionnaires distributed and recovered

\begin{tabular}{|l|c|c|}
\hline \multicolumn{1}{|c|}{ Type of questionnaire } & $\begin{array}{c}\text { Number of } \\
\text { questionnaires issued }\end{array}$ & $\begin{array}{c}\text { Number of valid } \\
\text { questionnaires recovered }\end{array}$ \\
\hline computer teacher questionnaire & 196 & 186 \\
\hline ordinary teacher questionnaire & 3475 & 2835 \\
\hline
\end{tabular}

Discussion with Teachers. The discussion members are including computer teachers, the course leader, backbone teachers and teachers with different levels of educational technology ability. The main purpose of discussion is to investigate the influence of information technology to teachers' personal development on information literacy. Discussion is very helpful to find the hidden problems and have a comprehensive understanding of the status quo.

\section{Analysis of Survey Results}

Teachers are in the face of students. They promote and popularize education information technology, and are the main perpetrators of information technology and curriculum integration. The quality of teachers' information literacy directly affects the effect of the implementation of e-education. The teachers' information consciousness and attitude, knowledge and skills, application and innovation, information technology teaching practice are analyzed in the following.

Teachers' Information Consciousness and Attitude. According to the results of the survey,52.1\% of the teachers have fully used and more accustomed to the use of information technology in teaching and preparing lessons, while $38.9 \%$ are generally accustomed. Information technology has become an indispensable tool for teaching and lesson preparation.

For the attitude of information technology and curriculum integration, most teachers, up to $72.7 \%$, believe that it is important to participate in the teaching reform of information technology and curriculum integration. But there are also $27.3 \%$ of the teachers who think it is not important because of disciplinary reasons or misunderstandings.

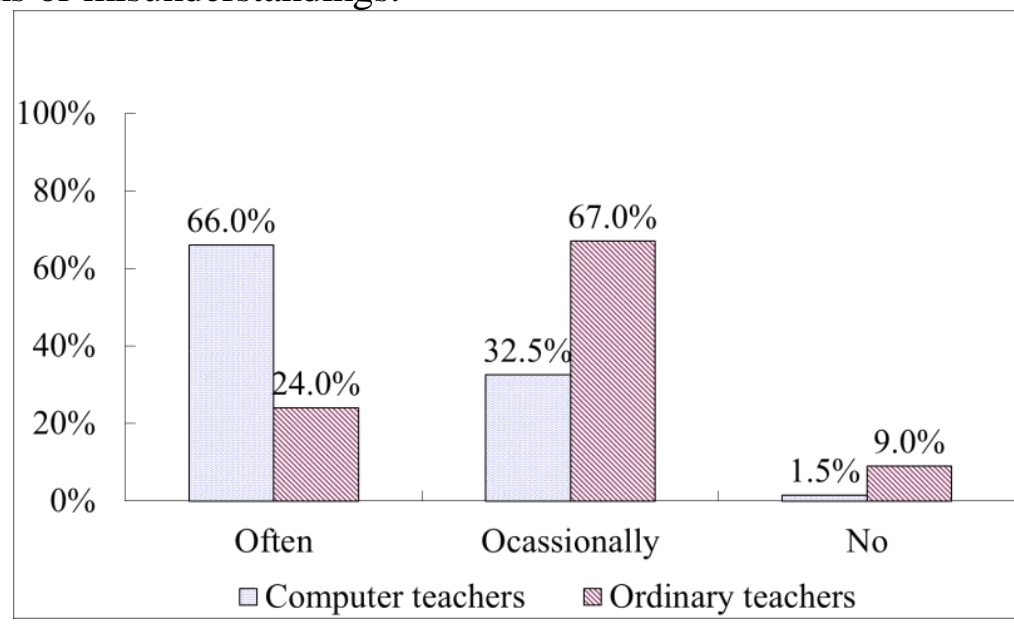

Figure 1. Teachers to impart information technology laws, regulations, ethics and norms 
In the aspect of the evaluation and reflection on the effect of application of information technology in teaching, only $48.3 \%$ of the teachers often have self-comment or mutual exchange. It shows that teachers' awareness on evaluation and reflection is relatively weak.

In the aspect of the sense of social responsibility while using information technology, only $24 \%$ of the ordinary teachers often impart knowledge of laws and regulations related to the use of information technology(See Fig. 1), ethical and moral standards, or demonstrate a healthy behavior and norms. Thus, there is a big problem in this area.

Knowledge and Skills. Survey shows that $37.2 \%$ of the teachers think they are familiar with the relevant theories and content of educational technology, while $35.1 \%$ of the teachers think they are familiar with the information technology equipment. $75.2 \%$ of the teachers often use the retrieval tools to retrieve the teaching resources. This shows that information retrieval tools have become an important channel for teaching resources and learning resources. Teachers are more proficient in basic office and teaching management software. More teachers are not proficient in other software tools, especially animation tools; up to $69.8 \%$ of the teachers are not very skilled (see Fig. 2). This shows that there are a lot of room for improvement in the use of information technology tools and software. The training need to be further strengthened.

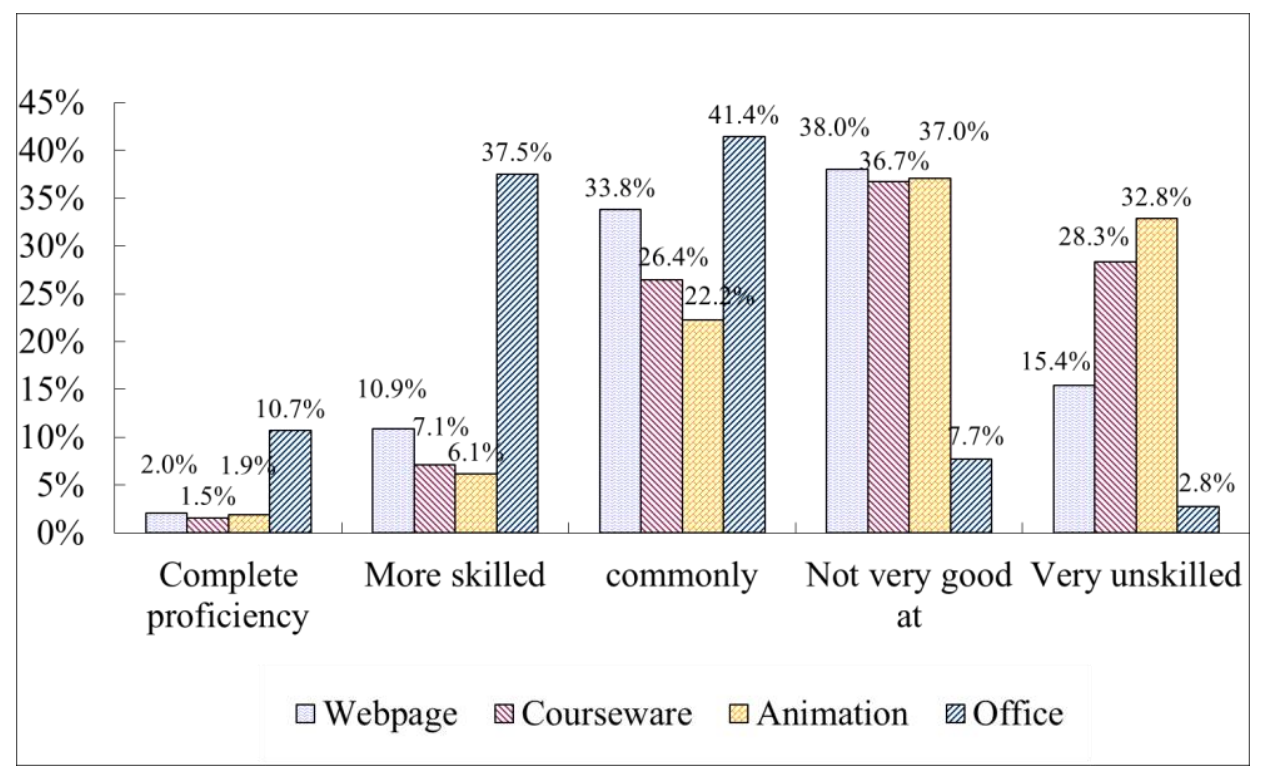

Figure 2. The use of information technology tools for ordinary teachers

Application and Innovation. The teaching application, research and innovation, communication and cooperation of the teachers are investigated. As shown in Fig. 3, some teachers often collect the teaching resources related to the subject and carry out the screening and integration, and provide opportunities for students to use information technology in practice. Most teachers can participate in the teaching and research activities related to the integration of information technology and curriculum. They make use of the network and other technical means to cooperate or communicate with colleagues or other school teachers in teaching and scientific research, and, to carry out the evaluation of teaching and learning. But from the survey data, except teaching innovation, most of the ordinary teachers participated in these activities occasionally. The initiative and enthusiasm is not strong enough. Teachers' information application and innovation in general is still in the state of deficiency.

Information Technology Teaching Practice. Statistical results of the survey data show that most teachers in the classroom use information technology in teaching accounting for a high proportion. Every year, the school has a certain special funds or equipment to support the teacher's information technology teaching practice. The teaching quality and the learning ability of students have been improved through the teaching practice of information technology. The main problem lies in the part of 
the school's special funds or equipment is not sufficient. And, good practice cases and high level of reward obtained are not too much. It is still need to be improved in teaching practice.

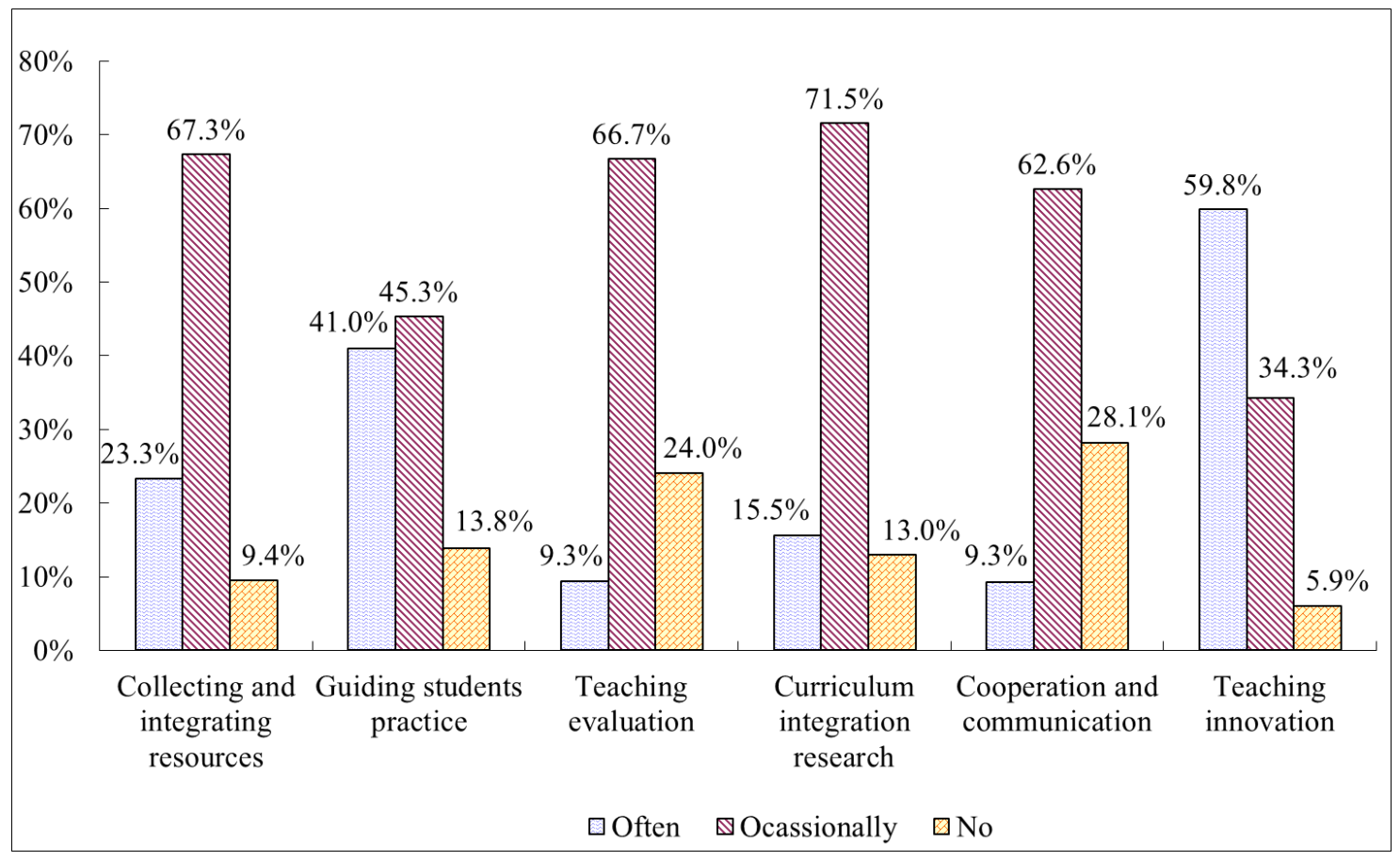

Figure 3. Research results of teachers' application and innovation

\section{Features, Problems and Suggestions}

Features and Advantages. Teachers in many years ago have participated in the integration of information technology and curriculum. The local government invested sufficient funds and the basic conditions of information technology in the domestic are in first-class. Computer teachers and ordinary subject teachers are able to realize the importance of e-education and have the awareness and ability to carry out the integration of information technology and curriculum. And teachers' information technology knowledge and ability is very strong. Teachers actively participate in the application and innovation of information technology research and practice, and achieved a lot of research results.

Existing Problems. Although the e-education in Foshan has many characteristics and advantages in the cultivation of teachers' information literacy, there are following problems:

The awareness of evaluation and reflection on the effect of e-education is not sufficient. Using information technology in teaching has two sides. Some schools emphases on the importance of modern teaching means too much, while others underestimate the importance of modern teaching means. They failed to do more in-depth evaluation and reflection of the e-education.

Some teachers do not impart sufficient knowledge of laws, regulations and ethical norms related to the use of information technology. There is no healthy behavior and norms given the actual demonstration. The demonstration of the health information technology application behavior and norms is not enough.

Some school's information related research is still relatively weak and lack of creativity. In the teaching process, the creative application of information technology is less. It is not very good to use information technology to communicate with students on the topics of learning.

Related Suggestions. First is to strengthen publicity and education, update information awareness and attitude. Teachers should be aimed at the actual needs of the curriculum, take the teaching effect as the guide, rational use information technology in the teaching process. Second is to adopt various promotion and incentive measures, to improve the initiative and creativity of teachers in information technology and curriculum integration, improve teachers' educational skills, and promote the 
development of e-education. Third, education departments at all levels should strengthen the construction of scientific research exchange platform to promote the use of platform in teaching and scientific research.

\section{Conclusions}

From the previous analysis, we can see that the overall level of information literacy of teachers in Foshan city is higher, and it plays a leading role in China. There are three main problems. The first is lack of mechanism and awareness to evaluate the effectiveness of educational information. The second is lack of the knowledge of laws, ethics, standards and regulations related to the use of information technology. The third is that teachers' e-education research ability is not strong enough. In the era of mobile Internet, Internet of things and the rapid development of Big data technology, the connotation of teachers' information literacy will also have a new development. The follow-up study will focus on the new requirements of teachers' information literacy under the development and application of new information technology.

\section{Acknowledgements}

This work is completed under the support of the Foshan Bureau of Education "Intelligent Education Evaluation System Optimization and Upgrading Service"(No. 0658-1501SZTCE279).

\section{References}

[1] Y.P. Zheng, Strategy Research about Improving the Teachers' Information Literacy in Secondary School (MS., Sichaun Normal University, China 2015), 5-10. (In Chinese)

[2] X. Wang, A Study on Information Literacy Education in American Primary and Secondary Schools (MS., Liaoning Normal University, China 2015), 4-8. (In Chinese)

[3] G.J. Fan, On the Construction of Primary and Secondary School Teachers' Information Literacy and Its Cultivating Approaches. Journal of Fujian Institute of Education, Vol. 5 (2013) No.03, 75-79.

[4] Y.L. Lu, Y. Zhang, Analysis of the Cultivation of Teachers' Information Literacy Based on e-Educational. Education theory and Practice, Vol.35 (2015) No.22, 38-40.

[5] S. Lv, Research on Teachers' Information Literacy in Primary and Middle School (MS., Northeast Normal University, China 2012), 5-14. (In Chinese)

[6] G.L. Sun, The Research of Secondary School Teachers' information Literacy in Jiangxi Province (MS., Nanchang University, China 2012), 4-25. (In Chinese)

[7] Y. Zhang, Research on the current situation and training strategies of junior middle school teachers' Information Literacy (MS., Liaoning Normal University, China 2013), 5-18. (In Chinese)

[8] X. Zou, Language Teacher's Information Literacy in the ICT context. Overseas English, Vol.15 (2012), No.15, 131-133.

[9] Y. He, T. Cui and N. Lu, the Research for College English Teachers' Information Literacy under ICT Environment. Science \& Technology Innovation Herald, Vol.11 (2014), No. 10, 121-123.

[10] W.N. Shi, a Study of the Influence of Local College English Teachers' Background Characteristics on the Information Literacy. Academics, Vol.20 (2014), No.12, 291-296. 